\title{
Prospects for Developing a Generalization Theory of 品 Physical Culture
}

\author{
Vasyl Sutula* \\ Kharkiv State Academy of Physical Culture, Ukraine
}

Received: May 30, 2018; Published: June 07, 2018

*Corresponding author: Vasyl Sutula, Professor, Doctor of Education, Kharkiv State Academy of Physical Culture, Ukraine, Europe

Abstract

The article presents the results of research on the problem of constructing a generalization theory of physical culture. It is concluded that such a theory is a system of knowledge in which of the common positions describes physical education, sports, physical recreation, as well as other related forms of social practice. It is shown that at present the problem of the allocation of the motive forces of the social mechanism, which is the basis of self-development of the sphere of activity of people connected with the use of physical exercises, is not fully solved.

Keywords: Theory; Activity; Social Phenomenon; Object Area; Self-Development

\section{Introduction}

The field of activity of people connected with the use of physical exercises is a sufficiently developed social phenomenon, which has a well-defined structure that has developed historically, whose elements have their own names - physical education, sports, physical recreation and other forms of social practice related to them. As a result of their versatile study, and this process has been going on for nearly two centuries, an immense array of information has been formed on the various facets of the functioning of these complex social phenomena. The logical consequence of the development of a system of knowledge about the above-mentioned forms of social activity of people was the formation of relevant theories (theory of sports, the theory and methodology of physical education, the theory of physical recreation). In their holistic perception, they answer the key question of how it is necessary to organize training, educational or recreational and recreational process within the framework of one form or another of the social activity of people associated with the use of physical exercises? The strategic direction in this approach is to study the procedural component of such activity, namely, the conditions and regularities of the pedagogical process, its content, means, methods and pedagogical technologies used in it, the principles of its organization, its results and much more.

In the second half of the last century, the scientific-pedagogical community began to form the idea that the object area of these theories is common, namely, the sphere of human activity is connected with using physical exercises. This led to an active search for ways of constructing a generalizing theory, which would reveal the driving forces, social mechanisms and objective laws of historical development of the defined sphere of activity of people [1,2]. An important role in this process was played by generalizing works that were published during the period of scientific study of this sphere of activity of people. One of the first such works was the five-volume encyclopedic work of B. McFadden's “Encyclopedia of MacFadden's Physical Culture" [3]. There were accumulated at the time knowledge about the influence of physical activity on human development and on various aspects of the functioning of its organism, in relation to the anatomy of the human body, human health, the causes of its diseases, describes the principles of first aid, as well as a lot of other information necessary in the practical life of each person. In 1925, the three-volume work of G Duferron's Theory of Physical Culture came out of print [4-6], in which the questions about the structure of the human body, the influence of physical exercises on the human body were revealed, the systematic of physical exercises and the methods described therein practical use, pedagogical and hygienic requirements for exercises with the use of physical exercises are highlighted. In 1991, the fundamental work of LP Matveev "Theory and Method of Physical Culture" [7] came out, in the first part of which the general characteristic of physical education (orientation, means, methods, principles) is given, the forms of constructing classes, the features of planning and control. In the second part of this work the theoretical and methodical aspects of contemporary sports are revealed, its role in the system of social 
phenomena is shown, the characteristic of the means, methods and content of sports training is given, the features of the construction of microcycles, mesocycles and the periodization of sports training are highlighted. The third part presents professional-applied forms of physical culture and the means and methodical bases of their construction are revealed. System the modern knowledge that has emerged in the field of human activity associated with the use of physical exercises is systematized in the work of D Wuest and C Bucher [8]. In this textbook, which has endured 12 editions, the authors provide a brief description of the philosophical approaches to the analysis of physical education and sports. The authors defined the role of physical education and sport in modern society, as well as the importance of fitness. In the second part of the work in a short form are presented historical information on the development of physical education and sports in various socio-economic formations and in different countries of the world, provides brief information on the physiological and biomechanical foundations of physical exercise and fitness, reveals the issues of psychology and sociology of physical education and sports, shows the role of sports in American culture, offers information on international amateur and professional sports and the Olympic Games. In the final part of the work, the authors reveal the prospects for the development of physical education and sport, which, in their opinion, are due to the social value of these forms of physical activity for human health and for its social well-being [9].

The above, as well as many other generalized scientific works, played an important role in shaping contemporary ideas about the field of activity of people associated with the use of physical exercises. At the same time, this approach to the formation of a system of knowledge, which was expressed in the "mechanical" combination of the totality of knowledge, reflecting the essence of the subject fields of theories of physical education, sports, physical recreation, did not give a holistic idea of a specific area of social practice. As a result of this approach, the system of knowledge did not acquire the features of the theory, since it did not have a single general theoretical basis. The foregoing suggests that the development of theoretical positions, which, from a single point of view, reflects the sphere of activity of people associated with the use of physical exercises, is a fundamental problem of constructing a generalizing theory. The result of special research on the problems of constructing such a theory was:

a) The wording of the generalization (consensus) definition of the term "physical culture" [10];

b) The allocation of specific features of the term "physical culture" in different countries of the world and the disclosure of the essence of the connection between the concepts of "physical culture", "physical recreation", "physical fitness" [11];

c) Coverage of the cultural and historical origins of the modern system of physical education and the allocation of prerequisites for the introduction into the national educational systems of the leading countries of Europe and the United States of the form of organization of physical exercises, as well as the discov- ery of the nature of the relationship between the concepts of "physical culture" and "physical education", [12];

d) The disclosure of the cultural and historical origins of modern sport [13], the wording of the general definition of the concept of "sport" and the definition of the peculiarities of its use in the process of developing a generalization theory of physical culture and sports theory [14];

e) The allocation of conceptual provisions of the generalization theory of physical culture, which is a system of knowledge in which one of the positions is described physical education, sports, physical recreation, as well as other related forms of social practice. In this system of knowledge the only general theoretical basis is the social mechanism of self-development of the sphere of human activity associated with the use of physical exercises, which is based on the law of "the relationship of needs and activities" [15].

Despite the wide range of problems solved in the above-mentioned publications, the problem of the allocation of the driving forces of the social mechanism that lies the basis of self-development of the sphere of activity of people connected with the use of physical exercises, for whose name in the domestic and foreign scientific practice is most often used the term "physical culture". The basis of such a mechanism is the social law "unity of needs and activities". It assumes that the activity of people, which characterizes the purposeful and definitely motivated activity of the subject at different intervals (past, present and future), is due to the need to meet various needs for exercise. Consequently, the structure of human needs, the principles of their formation, their interconnections and interactions, the patterns of their changes in the process of socio-cultural evolution is the key to understanding the features of the social mechanism, which defines the main trends in the historical development of the sphere of human activity associated with the use of physical exercises. The answer to the identified questions can be found in the comprehension of the biosocial essence of man through the prism of his practical activity.

\section{References}

1. Dyuperon GA (1925) Theory of Physical Culture T1: Basic Concepts: The device of the human body. Influence of physical exercises on the human body, Time, Leningrad.

2. Dyurperon GA (1925) Theory of Physical Culture T2: Systematics: Elements of Physical Culture, Time, Leningrad.

3. Dyurperon GA (1925) Theory of Physical Culture T3: Practical application of physical exercises. Selection of exercises. Hygienic requirements. Pedagogy of physical culture. The role of the teacher, Time, Leningrad.

4. Matveev LP (1991) Theory and method of physical culture (general principles of theory and method of physical education, theoretical methodological aspects of sport and professional-applied forms of physical culture), Physical culture and sports, Moscow.

5. Matveev LP (2009) Generalizing the theory of physical culture at the current stage of its formation. Theory and Practice of Physical Culture 9: 16-17.

6. Natalov GG (2004) Integration of the Science of Physical Culture. Theory and Practice of Physical Culture pp. 8. 
7. Vasyl Sutula (2017) Conceptual provisions of the generalization theory of physical culture. The theory and methods of physical education and sport 2(3): 555586.

8. Vasyl Sutula (2018) Summarizing the definition of the concept of "sport" as one of the basic constructs of generalizing the theory of physical culture and the theory of sports. Slobozhansky Scientific and Sport Bulletin 1: 64 .

9. Sutula V (2017) Cultural and Historical Origins of Modern Sport (the first message). Slobozhansky Scientific and Sport Bulletin 6: 62 .

10. Sutula Vo (2017) On the essence of the connection between physical culture and physical education (the first message). Theory and Methods of Physical Education and Sports pp. 3.

11. Sutula VO (2018) On the essence of the relationship between physical culture and physical education (second message). Theory and Methods of Physical Education and Sports pp. 4.

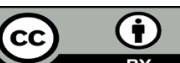

This work is licensed under Creative Commons Attribution 4.0 License

Submission Link: https://biomedres.us/submit-manuscript.php
12. Sutula VO (2016) On the essence of the connection between physical culture, physical recreation and physical fitness. Theory and method of physical education and sport pp. 4.

13. Sutula VO (2016) Physical Culture: The Preconditions of Theory. Theory and Methodology of Physical Education and Sports pp. 3

14. D Wuest, C Bucher (1995) Foundations of Physical Education and Sport, BurrRidge, WCB / McGraw-Hill, dubuque, Boston, 13: 9780070921382.

15. MacFadden B (1926) MacFadden's Encyclopedia of Physical Culture. MacFadden's Publications, INC, Hammond Press, WB Conkey Company Chicago, New York, Chicago, USA.

Assets of Publishing with us
$\begin{aligned} & \text { BIOMEDICAL } \\ & \text { RESERCHES }\end{aligned}$
- Global archiving of articles
- Immediate, unrestricted online access

